\title{
Ewing's Sarcoma as Second Malignant Neoplasm after Retinoblastoma: A Case Report
}

\author{
Rakesh Mittal $^{\mathrm{a}}$ Shafika Al Awadi ${ }^{\mathrm{a}}$ Omar Sahar $^{\mathrm{a}} \quad$ A.M. Behbehani ${ }^{\mathrm{b}}$ \\ ${ }^{a}$ Department of Medical Oncology, Hussain Maki Al Juma Centre for Specialized Surgeries, and \\ ${ }^{\mathrm{b}} \mathrm{Al}$ Bahar Eye Centre, Kuwait
}

\section{Key Words}

Retinoblastoma $\cdot$ Second malignant neoplasm •

Ewing's sarcoma

\begin{abstract}
Objectives: To report a case of a child with the hereditary form of unilateral retinoblastoma (RB), who developed Ewing's sarcoma of the right fibula 3 years after the enucleation of the right eye. Case Presentation and Intervention: The child was diagnosed as a case of RB of the right eye at the age of 9 months. He was fully investigated and found to have locally advanced RB with bone marrow involvement (ReeseEllsworth stage IVA). Enucleation was recommended to the family, but they refused. The patient received chemotherapy and diode laser thermotherapy in Kuwait and the UK. He had a local relapse after 11 months and subsequently underwent enucleation of the right eye. After 3 years, he was investigated for a small swelling in his right lower leg. After extensive investigations, it was reported as Ewing's sarcoma. He was treated with chemotherapy, surgery (complete excision of the fibula) and high-dose chemotherapy followed by autologous stem cell transplantation. The child is now nearly 2 years after completing the treatment and is disease free. Conclusions: This case confirms the increased risk of a second malignant neoplasm (SMN) in children with hereditary $\mathrm{RB}$. These children need a very close follow-up for the early diagnosis of SMNs or even subsequent malignancies.
\end{abstract}

Copyright $\odot 2007$ S. Karger AG, Basel
(C) 2007 S. Karger AG, Basel

1011-7571/08/0171-0084\$24.50/0

Fax +4161306 1234

E-Mail karger@karger.ch

www.karger.com
Accessible online at:

www.karger.com/mpp

\section{Introduction}

Retinoblastoma (RB) is the most common form of malignant eye tumour found among children. It could develop due to hereditary and non-hereditary reasons. Patients who suffer from the hereditary type have a germ line mutation of the $R B 1$ gene, present at an early age and usually have bilateral disease, while children without germ line mutation of the $R B 1$ gene present at a later age and develop unilateral disease. Children with the hereditary form of RB are prone to second malignant neoplasms (SMNs). These second malignancies are usually in the form of bone or soft-tissue sarcomas, which may or may not be related to radiation therapy. Children with a germ line mutation of the $R B 1$ gene and who receive radiation therapy as part of their treatment for $\mathrm{RB}$ are at the risk of developing SMNs [1].

We report the case of a child with the hereditary form of unilateral RB, who developed Ewing's sarcoma of the right fibula 3 years after the enucleation of the right eye.

\section{Case Report}

Based on a family photograph, which showed a yellow reflex in the right eye (cat's eye reflex) the patient, aged 9 months, was taken to the eye centre and was found to have RB of an advanced stage. Subsequently he was fully investigated at the ophthalmic centre and was found to have locally advanced RB. He was referred to the Paediatric Oncology Unit for treatment. Bone marrow aspiration/ biopsy was done as part of a staging work-up, and it revealed involvement of RB cells. He was finally classified as Reese-Ellsworth stage IVA. As there was no vision in the right eye, enucleation was recommended to the family, but they refused. The patient was 
started on the carboplatin, vincristine and etoposide chemotherapy protocol. After receiving 5 courses he was taken to the UK where he received a further 2 courses of chemotherapy and 2 sittings of diode laser thermotherapy. He achieved partial remission (more than $50 \%$ reduction in tumour size). A year later, he relapsed and subsequently underwent enucleation of the right eye and was followed up by the ophthalmic surgeon. Three years later, he presented with a small swelling over the right lower leg. An X-ray of the leg revealed a lytic lesion in the mid shaft of the right fibula. A bone scan was positive. Fine-needle aspiration cytology from the lesion reported it to be a small round cell tumour and he underwent excision biopsy of the lesion. Initially it had been reported as metastatic RB, but after extensive immunohistochemistry it was reported as Ewing's sarcoma. The family took him to M.D. Anderson Hospital, Houston, Tex., USA, where he was treated with chemotherapy, followed by surgery (complete excision of the fibula), another round of high-dose chemotherapy and finally autologous stem cell transplantation. Fluorescent in situ hybridization analysis of the tissue sample of the fibula biopsy taken from Kuwait confirmed the presence of chromosomal translocation consistent with the diagnosis of Ewing's sarcoma. Genetic tests on the original RB specimen confirmed the presence of translocation involving the $R B 1$ gene [46 XY, t (4;13) (p14;q14)]. His left eye has not shown signs of disease activity, and his vision in that eye is normal. Two years later on, he is in complete clinical and radiological remission.

\section{Discussion}

SMNs are not uncommon in patients with $\mathrm{RB}$, who have germ line mutation of the $R B 1$ gene as previously reported $[2,3]$. Our patient developed SMN 4.3 years after the initial diagnosis of $\mathrm{RB}$; however, this period is much shorter than previous reports of 14.2 years [2] or 18 years (range $10-32$ years) [3-5].
These SMNs can present in a variety of histologies, most commonly being osteosarcoma [2-5]. Ewing's sarcoma as SMN is quite uncommon $[6,7]$ as in our case.

The SMNs after RB usually occur in radiation fields, but can also occur in non-irradiated fields most commonly in the extremities $[2-5,8]$ as in our patient.

In the majority of cases, SMNs develop in children with bilateral RB [8-11], but it can occur in children with unilateral retinoblastoma [9] as in the present case. The clinical outcome of the children who develop SMN depends upon the location and response of the second tumour to treatment, requiring aggressive chemotherapy with adjuvant radiotherapy [3-5]. In a number of studies, children with SMNs who were aggressively treated with multimodality therapy survived longer than those without aggressive treatment $[3-5,12]$. Our patient who underwent very aggressive treatment, which included induction chemotherapy, surgery and high-dose chemotherapy followed by autologous stem cell transplantation, is surviving and is being followed up very closely.

\section{Conclusions}

This report confirms that patients suffering from $\mathrm{RB}$ with germ line mutation are at an increased risk of developing SMNs, which can occur as late as 30 years or even later after the initial treatment for RB. These patients require a very close follow-up with specific instructions to look for any evidence of SMNs. Once diagnosed as having secondary neoplasms, they need aggressive treatment to achieve a second cure.

\section{References}

1 Pizzo PA, Poplack DG: Principles and Practice of Pediatric Oncology, ed 3. New York, Lippincott-Raven, 1997, p 713.

- 2 Fontanesi J, Parham DM, Pratt C, Meyer D: Second malignant neoplasms in children with retinoblastoma: the St. Jude Children's Research Hospital experience. Ophthalmic Genet 1995;16:105-108.

3 Aerts I, Pacquement H, Doz F, Mosseri V, Desjardins L, Sastre X, Michon J, Rodriguez J, Schlienger P, Zucker JM, Quintana E: Outcome of second malignancies after retinoblastoma: a retrospective analysis of $25 \mathrm{pa}$ tients treated at the Institut Curie. Eur J Cancer 2004;40:1522-1529.

-4 Dunkel IJ, Gerald WL, Rosenfield NS, Strong EW, Abramson DH, Ghavimi F: Outcome of patients with a history of bilateral retinoblastoma treated for a second malignancy: the Memorial Sloan-Kettering experience. Med Pediatr Oncol 1998;30: $59-62$.

5 Smith LM, Donaldson SS, Egbert PR, Link MP, Bagshaw MA: Aggressive management of second primary tumors in survivors of hereditary retinoblastoma. Int J Radiat Oncol Biol Phys 1989;17:499-505.

-6 Schifter S, Vendelbo L, Jensen OM, Kaae S: Ewing's tumor following bilateral retinoblastoma: a case report. Cancer 1983;51: 1746-1749.

7 Spunt SL, Rodriguez-Galindo C, Fuller CE, Harper J, Krasin MJ, Billups CA, Khoury JD: Ewing sarcoma - Family tumors that arise after treatment of primary childhood cancer. Cancer 2006;107:201-206.

8 Abramson DH, Ronner HJ, Ellsworth RM: Second tumors in nonirradiated bilateral retinoblastoma. Am J Ophthalmol 1979;87: 624-627.
Ewing's Sarcoma as Second Malignant Neoplasm after Retinoblastoma 